\title{
ENVIRONMENTAL SUSTAINABILITY: BIOACTIVITY OF LEUCAENA LEUCOCEPHALA LEAVES AND PESTICIDE RESIDUE ANALYSIS IN TOMATO FRUITS
}

\author{
Oluwatoyin Adenike Fabiyi ${ }^{1}$, Gabriel Ademola Olatunji ${ }^{2}$
}

\author{
${ }^{1}$ Department of Crop Protection Faculty of Agriculture, University of Ilorin, Ilorin, PMB 1515, Nigeria \\ ${ }^{2}$ Department of Industrial Chemistry, Faculty of Physical Sciences, University of Ilorin, Ilorin, PMB 1515, Nigeria \\ Link to this article: https://doi.org/10.11118/actaun.2021.042 \\ Received: 25. 12. 2017, Accepted: 15. 6. 2021
}

To cite this article: FABIYI OLUWATOYIN ADENIKE, OLATUNJI GABRIEL ADEMOLA. 2021. Environmental Sustainability: Bioactivity of Leucaena leucocephala Leaves and Pesticide Residue Analysis in Tomato Fruits. Acta Universitatis Agriculturae et Silviculturae Mendelianae Brunensis, 69(4): 473-480.

\begin{abstract}
Field studies were conducted on the application of Leucaena leucocephala leaf extracts as an alternative to carbofuran a synthetic nematicide, while possible residues of carbofuran in tomato fruits were also analysed. Acetone, methanol and petroleum ether fractions of the leaves of $L$. leucocephala were applied at $200 \mathrm{mg} / \mathrm{mL}$ in variants of $100 \mathrm{~mL}, 150 \mathrm{~mL}$ and $200 \mathrm{~mL}$ to a naturally nematode infested field. Comparison was made with carbofuran a synthetic insecticide and nematicide. Samples of tomato fruits from carbofuran treated and untreated beds were extracted with ethyl acetate for residual pesticide analysis to ascertain the exceedance of the maximum residue limit (MRL). Results revealed that pesticide residue was significantly $(p=0.05)$ higher in plots treated with carbofuran compared with standard MRL for carbofuran in tomatoes. Crude extracts of L. leucocephala were as effective as carbofuran, while the fraction was however significantly better in producing higher numbers of fruits and reduced nematode population in root and soil of tomato plants.
\end{abstract}

Keywords: Meloidogyne incognita, environmental pollution, Leucaena leucocephala, carbofuran, chromatography, tomato, pesticide residue

\section{INTRODUCTION}

Pest and diseases are a significant threat to agricultural crop production due to the losses they cause to a wide range of crops. The pest attack results in decreased yield, reduction in quality of crops and loss of income (Atolani and Fabiyi, 2020). There is the need for farmers to combat pests and disease causing organisms so as to protect their valuable crops and thus increase yield (Fabiyi et al., 2018). Plant parasitic nematodes are one of the major causes of economic loss to crops worldwide particularly in tomato fields (Stirling and Pattison, 2008; Fabiyi, 2018). The use of pesticides then came into play especially when crop failure is imminent; they provide immediate solution in agricultural fields. As farmers focus on protecting their valuable crops, little did they know that they are constantly exposed to pesticide poisoning (Abhilash et al., 2009). Hazards of pesticide vary with the extent of human exposure; moderate hazards include blurred vision, skin diseases, flu and headache. Severe human health hazards encompass blindness, paralysis and death (Min et al., 2006). The use of nematicides though significantly brought down nematode populations on farm fields below economic threshold level, other farm practices such as use of farm yard manure, incorporation and application of plant materials were reported as being slow and less effective (Daramola et al., 2013). Carbofuran (2,3-dihydro-2,2-dimethyl-benzofuran- 
$7-y l-N$-methylcarbamate) is a common insecticide/ nematicide used in nematode control. It is toxic and not environmentally friendly due to its high solubility in water (700 ppm), consequently, it has the potential to contaminate lakes, streams, and groundwater (Nicosia et al., 1991; Fabiyi et al., 2012). Carbofuran is metabolized via oxidation to 3-hydroxycarbofuran and 3-ketocarbofuran; it also undergoes hydrolysis under alkaline conditions (US EPA, 1990). Several metabolites have been obtained in animal studies which include carbofuranphenol, 3-hydrocarbofuran-7-phenol, N-hydroxymethyl carbofuran, 3-ketocarbofuran, and 3-ketocarbofuran phenol (Eisler, 1985). Carbofuran though banned in developed countries is still available to farmers for use in Nigeria. It is the sole nematicide obtainable and with its dual function as an insecticide the regularity of use is strikingly disturbing (Fabiyi et al., 2020a). This has instinctively heightened the contamination level of crops and soil. In view of the environmental pollution caused by application of carbofuran there is the need to investigate other alternatives such as eco-friendly bio pesticides (Fabiyi et al., 2020b; Fabiyi, et al., 2020c). The effect of Leucaena leucocephala fractions and extracts on $M$. incognita population in tomato plants on the field compared with carbofuran was investigated in this study. Furthermore, the study evaluated possible carbofuran residue in tomato fruits to appraise the residue level after harvest and affirm if this transcends the maximum residue limit (MRL) legal standard expected in correct application of pesticides which corresponds to the normal practice in agriculture. Leucaena leucocephala belongs to the family Leguminosae (Oakes, 1968; Chen and Wang, 2010). The various parts have been found to be medicinal including antihelmintic and control of stomach diseases (Ademola et al., 2005; Syamsudin and Partomuan, 2010), while the seed gum is used as a binder in tablet formulations (Deodhar et al., 1998).

\section{MATERIALS AND METHODS}

\section{Collection and Preparation of Plant Materials}

Leucaena leucocephala leaves were collected from the mother tree at Idi-ayunre village in Ibadan area of Oyo state Nigeria. The materials were air dried under ambient conditions and were divided into four equal parts of 1650 grams individually. Each portion was extracted with petroleum ether, methanol, and acetone separately. The extracts were decanted and filtered after five days of cold extraction and they were coded LCNL/Pet, $\mathrm{LCNL} / \mathrm{Me}_{2} \mathrm{CO}$ and LCNL/MeOH, which represents Leucaena leucocephala petroleum ether, acetone and methanol extracts. LCNL/frcn are chromatographic fractions from methanol extract, while LCNL/ODR represents the plant material that was incorporated directly into the soil.

\section{Fractionation}

A part of the methanol extract (LCNL/MeOH) was subjected to fractionation in a column packed with silica gel 60 (80-200 mesh) serving as the stationary phase and n-hexane (alone), n-hexane/ethyl acetate (ratio 1:1), ethyl acetate/n-hexane (ratio 2:1), ethyl acetate/n-hexane (ratio $3: 1$ ) and finally ethyl acetate (alone) as the eluting solvent. This procedure afforded seventeen fractions some of which were pure enough for spectroscopic analysis.

\section{Spectroscopic Measurements}

Proton Nuclear Magnetic Resonance ( ${ }^{1} \mathrm{H}$ NMR) was recorded on Bruker AMX 400. Chemical shifts are in ppm which is relative to TMS as internal standard while coupling constants are in Hz. Buck 500M spectrophotometer with $\mathrm{KBr}$ pellets was used for the Infra-red analysis. Gas Chromatography-Mass Spectroscopy was carried out with Agilent 7890A GC/MS equipped with a Quadrupole Mass Spectra Detector and an Auto-sampler.

\section{Initial/Final Nematode Population Count}

Soil samples were taken from the field at planting, a month after inoculation, a month after treatment application and finally at harvest using systemic sampling method, in order to identify the native nematode genera in the soil and their population. Twenty soil cores were taken from each bed $(10 \mathrm{~cm}$ diameter and $25 \mathrm{~cm}$ deep) using a soil auger of $1.9 \mathrm{~cm}$ diameter. The samples were thoroughly mixed to form a bulk sample for each bed and were sealed in polythene bags with proper labels. In the laboratory $250 \mathrm{~mL}$ of each bulk sample was used for nematode population count and identification. Extraction of nematodes was done using the Whitehead and Hemming (1965) tray method of nematode extraction. The resulting nematode suspension was transferred into a $500 \mathrm{~mL}$ beaker and left to settle for 3 hours, water in the beaker was later reduced by siphoning (Caveness, 1975). Remaining nematode suspension was transferred into the Doncaster (1962) counting dish for identification and counting of the different genera and species. The identification of plant parasitic nematode was done using the key of Mai and Lyon (1975) and was however supported with the crop protection compendium nematode key (CABI, 2001).

\section{Inoculum Culture}

Heavily galled roots of Celosia argentea infected with Meloidogyne incognita was obtained from National Horticultural Research Institute Ibadan Nigeria (NIHORT). The inoculums were multiplied in a pot culture of Celosia argentea cV TLV8 in the screenhouse of the Faculty of Agriculture, University of Ilorin, Ilorin, Nigeria. Eggs were later obtained from these roots of $C$. argentea using $0.6 \%$ sodium hypochlorite solution in $600 \mathrm{~mL}$ beaker (Hussey and Barker, 1973). The egg suspension was 
poured via a stack of 73,56 and $25 \mu \mathrm{m}$ aperture mesh (Fabiyi et al., 2020a). Eggs retained on the $25 \mu \mathrm{m}$ mesh were gently washed under stream tap water, transferred in to a beaker and was left to hatch into juveniles in the laboratory. Hatched eggs were separated from the juvenile using the pie-pan method, juveniles were counted with the Doncaster (1962), counting dish under the stereo microscope at $100 \times$ magnification, one $\mathrm{ml}$ was standardised to contain approximately 450 juveniles.

\section{Field Experiment}

Two rain fed trials were conducted at Aba-pannu area of Apata Ibadan, Oyo state Nigeria $\left(7^{\circ} 23^{\prime} 47^{\prime \prime} \mathrm{N}\right.$ $3^{\circ} 55^{\prime} 0^{\prime \prime} \mathrm{E} / 7.39639^{\circ} \mathrm{N}$, with mean rainfall $1420.06 \mathrm{~mm}$, relative humidity of $74.55 \%$ and temperature $26.46^{\circ} \mathrm{C} / 21.42^{\circ} \mathrm{C}$ (maximum and minimum respectively), between September to December year 2016 and 2017. The experimental site had a history of carbofuran usage of over five years. Experimental design was a Randomized Complete Block Design with six treatments (LCNL/Pet, $\mathrm{LCNL} / \mathrm{Me}_{2} \mathrm{CO}, \mathrm{LCNL} / \mathrm{MeOH}, \mathrm{LCNL} /$ frcn, LCNL/ODR and $\mathrm{CBFN})$ at four rates of application (0, 1, 2 and 3$)$ and three replicates for each treatment $(6 \times 4 \times 3)$. A total of seventy-two experimental beds were used in all and each bed was $4 \mathrm{~m} \times 1 \mathrm{~m}$. Two weeks old tomato seedlings (cv Roma) were transplanted on to the beds at a spacing of $50 \mathrm{~cm}$ in the row and $75 \mathrm{~cm}$ between the rows (Gudugi et al., 2012). A week after transplanting each plant was inoculated with approximately 450 juveniles of $M$. incognita. The inoculated tomato plants were treated after two weeks with $100 \mathrm{~mL}, 150 \mathrm{~mL}$ and $200 \mathrm{~mL}$ of fractions and crude extract (from a stock solution of $200 \mathrm{mg}$ per $\mathrm{mL}$ ) around the base of each plant (Fabiyi, 2019). The powdered plant material was applied at the rate of 50, 75 and $100 \mathrm{~g}$ as soil mix. The crude and the fractions were admixed with soil, while carbofuran was applied at the manufacturers recommended dosage. Tomato fruits were harvested as they ripen and overall cumulative harvest were recorded in terms of number and total weight of fruits per plant. The quality was also taken into account. Data collected was subjected to analysis of variance using GenStat 5.32 and separation of means done with Tukey's honest significant difference test (Fabiyi, 2020).

\section{Residue Analysis}

Four tomato fruits were randomly picked from each bed on the field, stored at $4^{\circ} \mathrm{C}$ and were analysed in batches according to treatments. Fifty grams $(50 \mathrm{~g})$ of fresh tomato fruits were chopped and homogenized with $50 \mathrm{~mL}$ of ethyl acetate and $10 \mathrm{~g}$ of anhydrous sodium sulphate in an Erlenmeyer flask. The mixture was shaken in a horizontal shaker for an hour after which it was filtered with Whatman's no 1 filter paper. The extract was decolourized with activated charcoal and the solvent was removed with suction pressure using a vacuum pump. The dried extract was redissolved in acetonitrile for final analysis using high performance liquid chromatography (HPLC).

\section{High Performance Liquid Chromatography}

The HPLC analyses were carried out on Shimadzu (Nexera MX) $\mu$ Bondapak $C_{18}$ column at length $100 \mathrm{~nm}$, identity of $4.6 \mathrm{~nm}$ and a thickness of $7 \mu \mathrm{m}$ respectively. The samples were injected at $10 \mu \mathrm{L}^{-1}$. The mobile phase consisted of acetonitrile and water in ratio 60 to 40 and the analyte was detected using diode array adjusted to $254 \mathrm{~nm}$ for absorption measurement at a pump pressure of $15 \mathrm{mpa}$. The compounds were isocratically eluted at a flow rate of $5 \mathrm{~mL}$.min ${ }^{-1}$ for the samples. The detector was connected to a computer for data processing.

\section{RESULTS}

\section{Spectroscopy}

Result of the GCMS analysis of the fraction revealed compounds which include benzofuranone (13.1\%), 1-cyclohexylnonene (20.2\%), pentadecanoic acid-14-methyl-methyl ester (11.5\%), Cyclohexanecarboxylic acid, decyl ester (16.8\%), 6,10,14-trimethyl-2-pentadecanone $(8.5 \%)$, squalene $(10.1 \%)$ and caffeic acid $(9.1 \%)$ as the principal constituents and they constitute $89.3 \%$ of the total. NMR spectrum established the presence of an aldehyde at 9.14, 9.06 and methylene groups at $1.7 \mathrm{ppm}$. IR $\left(\mathrm{KBr} \mathrm{cm} \mathrm{cm}^{-1}\right)$ indicates the presence of hydroxyl group (3321 and $1042 \mathrm{~cm}^{-1}$ ), a carbonyl $\left(1715 \mathrm{~cm}^{-1}\right)$ and an aromatic ring $\left(2990 ; 824 \mathrm{~cm}^{-1}\right)$.

\section{Field}

The results of the effects of treatments on tomato plants under $M$. incognita infection is depicted in Figs 1-8. The organic solvent extracts of $L$. leucocephala and carbofuran significantly $(\mathrm{p}=0.05)$ increased the vegetative growth of tomato, which translated into the higher yield observed in the treated tomato plants as opposed to the untreated plants. The mean number of fruits of plants treated with chromatographic fractions from L. leucocephala (LCNL/frcn) was significantly $(p=0.05)$ more than those obtained from acetone and methanol crude extracts (LCLN/Me $2 \mathrm{CO}$; $\mathrm{LCNL} / \mathrm{MeOH}$ ), there was however no significant difference between carbofuran (CBFN) treated plants and the organic solvent extracts. The plant materials incorporated in to the soil as soil admix (LCNL/ODR) and petroleum spirit extract (LCNL/Pet) were not as effective as all the other treatment (Fig. 1). The rate of application of the treatment materials is shown in Fig. 2, the highest level (level 3) produced more numbers of fruits against the untreated control plants (level 0). L. leucocephala fractions also produced significantly heavier fruits, carbofuran and the crude extracts remained at par, 


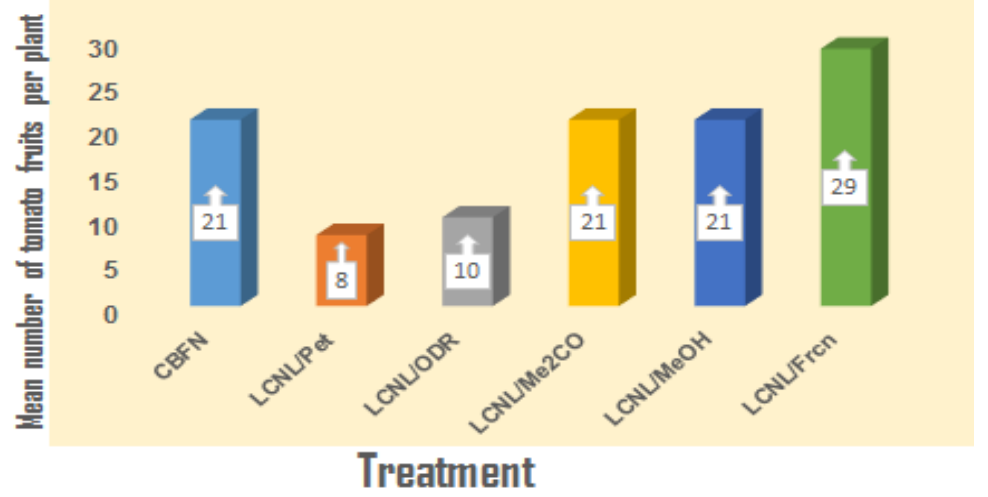

1: Effect of treatment on mean number of tomato fruits

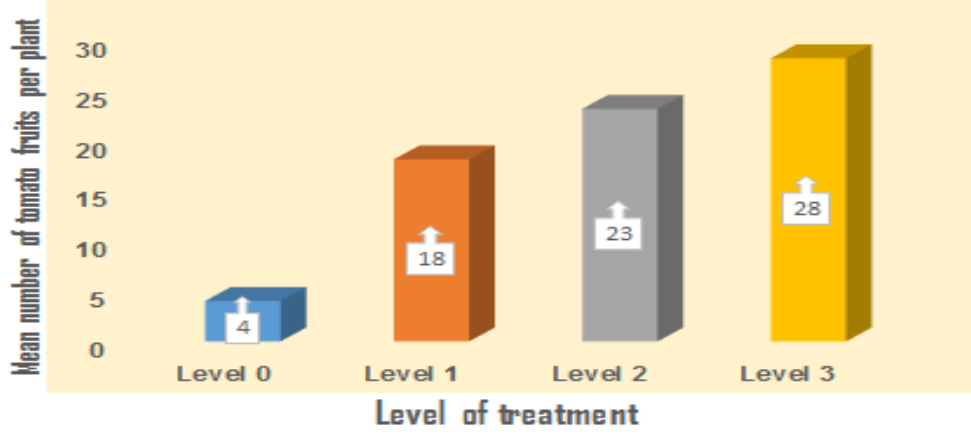

2: Effect of level of application on mean number of tomato fruits

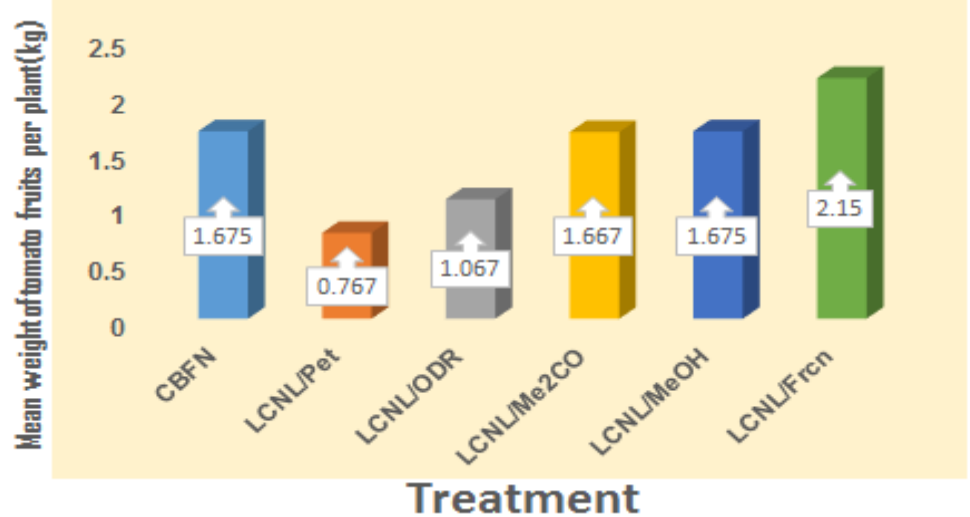

3: Effect treatment on mean weight of tomato fruits

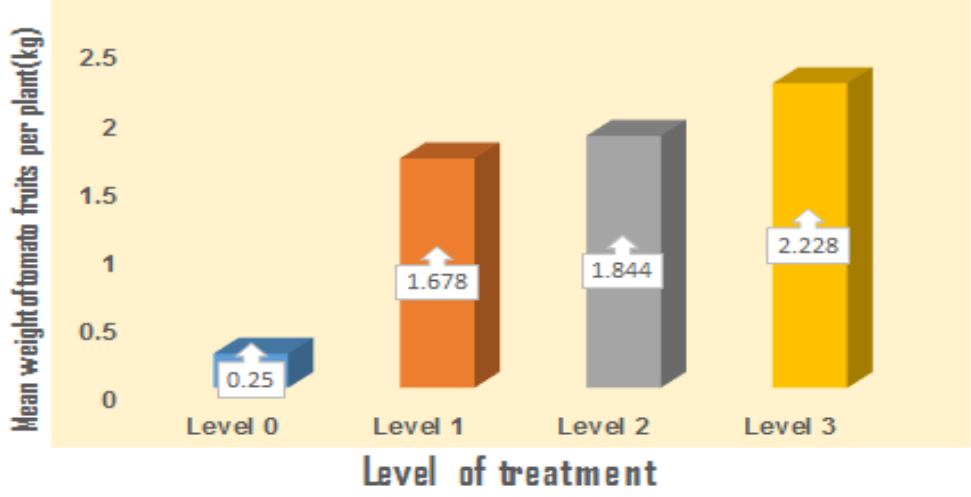

4: Effect of level of application on mean weight of tomato fruits 


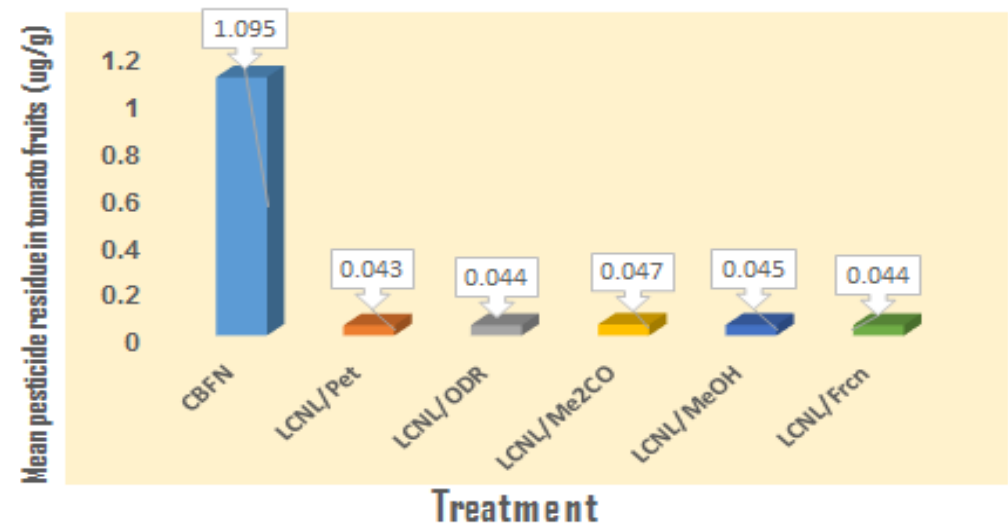

5: Effect of treatments on mean pesticide residue in tomato fruits

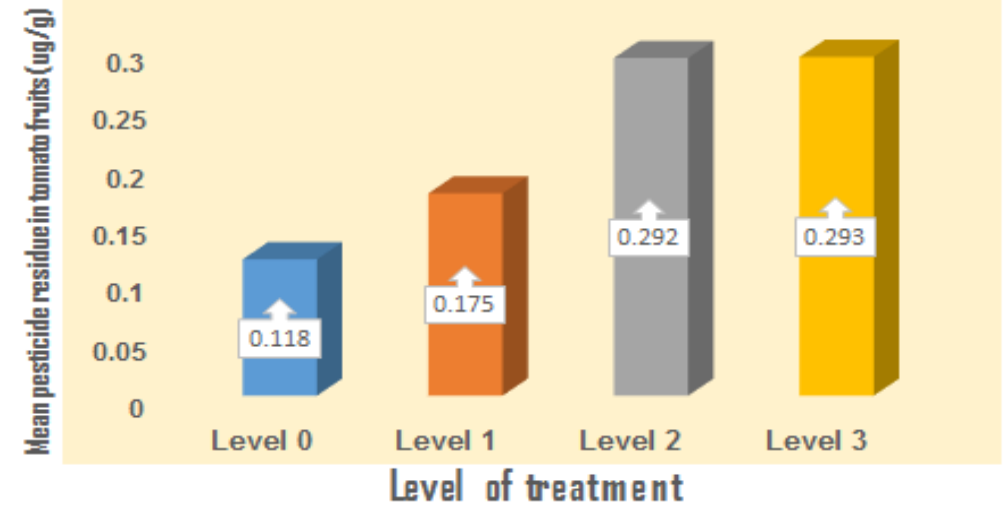

6: Effect of treatments levels on mean pesticide residue in tomato fruits

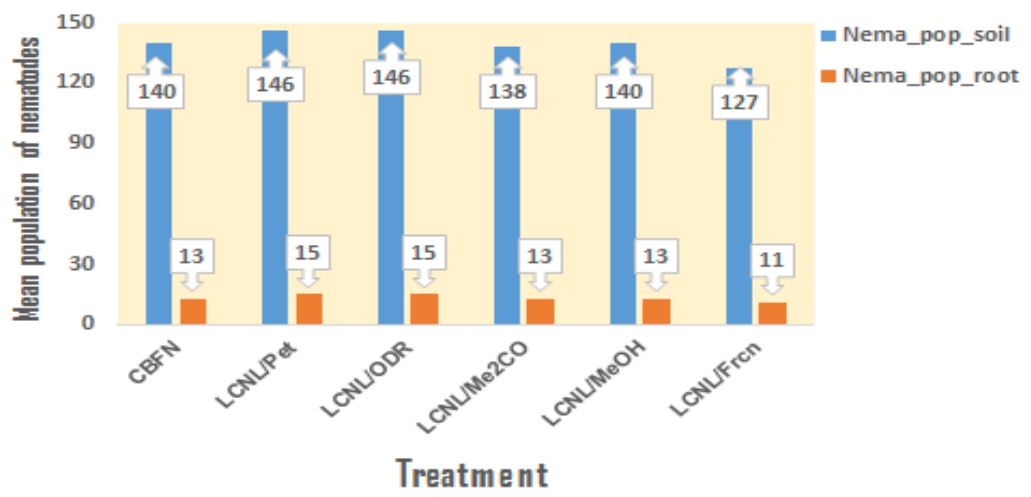

7: Effect of treatments on mean nematode population

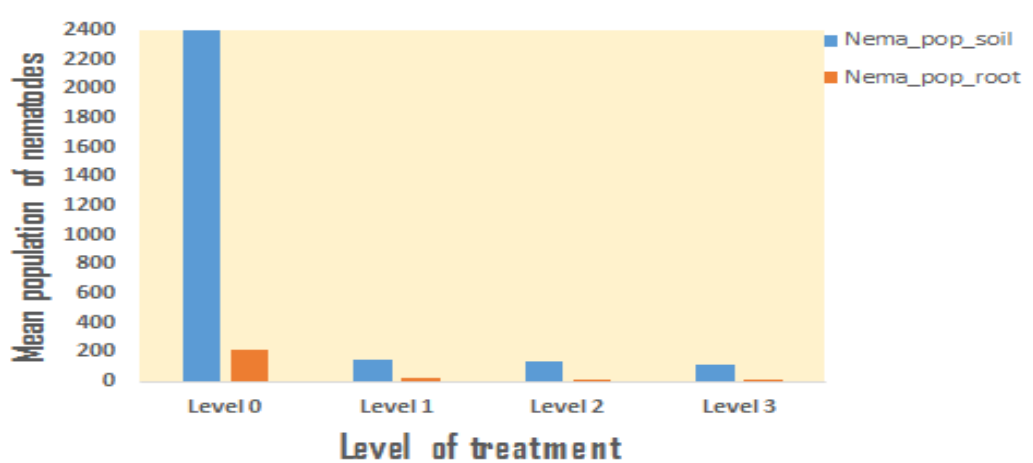

8: Effect of treatment levels on mean nematode population 
while the petroleum spirit extract had significantly lower fruit weight (Fig. 3). The highest dosage of treatment also recorded a higher mean fruit weight (Fig. 4). Mean pesticide residue in tomato plants is depicted in Fig. 5, the plots treated with carbofuran had the highest residue in the tomato fruits, while the bio-pesticide treated plants had significantly lower amount of residue remaining in the fruit after harvest. Nematode population was obviously low in the roots and soil of all the treated plants compared to the untreated control tomato plants, the highest level of treatment application was significantly $(\mathrm{p}=0.05)$ more effective than all the other levels (Figs. 6 and 7).

\section{DISCUSSION}

Medicinal plants are presently being studied as potential sources of bio-pesticides in the control of plant parasitic nematodes. The GCMS results of the constituents of $L$. leucocephala corroborate the reports of Salem et al. (2011). They reported the presence of benzofuranone and several fatty acids and their methyl esters. Rasmia et al. (2014) identified caffeic acid in the aerial parts of $L$. leucocephala. The presence of squalene was equally reported by Chung-Yi Chen and Yau-Der Wang (2010). The methanol (LCNL/MeOH) and acetone (LCLN/Me $\mathrm{Me}_{2}$ ) extracts were not significantly different from carbofuran. Methanol extracts of $L$. leucocephala was reported to show moderate nematicidal activity against the pine wood nematode Bursaphelenchus xylophilus (Mackeen et al., 1997). Ademola et al. (2005), investigated the anthelmintic effect of chromatographic fractions of L. leucocephala (Lam.) de wit seed extract. The extracts killed infective larvae of $H$. contortus of sheep in a concentration-dependent manner. The fraction contains alkaloids, tannins and flavonoids. The most effective fraction however contains polar polyphenol compounds. The nematicidal effect of aqueous extract of leaves and roots of $L$. leucocephala was reported by Adekunle and Akinlua (2007). They observed reduction in nematode population, reduced galling and nematode reproduction rate.
The activity observed was substantiated by the presence of secondary metabolites in the extract of $L$. leucocephala. The nematicidal activity of quercertin a phenolic compound isolated from L. leucocephala was reiterated by Adekunle and Aderogba (2008). They reported a high level of toxicity to $M$. incognita eggs. $28 \%$ egg hatch was recorded over a period of 14 days and 100\% mortality in four days of exposure to $0.8 \%$ concentration of quercetin. Similarly, Oliveira et al. (2011) reported a 90\% nematicidal effectiveness of the acetone and water extracts of the aerial parts of $L$. leucocephala. The results in this study was substantiated by the documentations of previous investigations on $L$. leucocephala. Application of fractions and extracts from the plant significantly reduced pesticide residue in tomato fruits albeit the erstwhile application of carbofuran on the experimental site. This signifies that carbofuran residue in soil was subdued by the extracts from the test plant and the absorption of residual carbofuran in soil by tomato plants vis-a-vis the fruits was lessened. The European union (E.U) in its regulation 2015/399 of 25th February 2015 where Annexes II, III and V of Regulation (EC) No. 396/2005 of European Parliament and Council was amended, regarding maximum residue level for carbofuran, carbosulfan and benfuracarb in fruiting vegetables (solanacea) where under in tomato, classified with code number 0231010 is allotted a low MRL of $0.002 \mathrm{mg} / \mathrm{kg}$ (Regulation, 2015). Be that as it may, the MRL set for carbofuran by the Japanese Food Chemical Research Foundation is $0.3 \mathrm{ppm}$ (Manprakash, 2007). The EU MRL is much lower than the Japanese recommended value. The residue value of tomatoes treated with carbofuran in this research is exceedingly higher than standards, while the values from tomato fruits treated with extracts of $L$. leucocephala are appreciably low relatively to $0.3 \mathrm{ppm}$. The treatment values of $0.044 \mathrm{ug} / \mathrm{g}$ is also lower than the EU set value. The plants extracts depict higher safety margin than carbofuran. It is thus safer than carbofuran and could be employed for use in tomato cultivation.

\section{CONCLUSION}

The application of Leucaena leucocephala leaf extracts offer alternatives to synthetic pesticide which cause pollution in the environment and consequently reducing synthetic pesticide residues in fruits and vegetables as observed in this study.

\section{REFERENCES}

ABHILASH, P. C. 2009. Pesticide use and application. Journal of Hazard Materials, 165(1-3): 1-12.

ADEKUNLE, O. K. and AKINLUA, A. 2007. Nematicidal effects of Leucaena leucocephala and Gliricidia sepium extracts on Meloidogyne incognita infecting okra. Journal of Agricultural Sciences, 52(1): 53-63.

ADEKUNLE, O. K. and ADEROGBA, M. A. 2008. Characterisation of an antinematicidal compound from Leucaena leucocephala. Australasian Plant Disease Notes, 3(1): 168-170. 
ADEMOLA, I. O., AKANBI, A. I. and IDOWU, S. O. 2005. Comparative Nematocidal Activity of Chromatographic Fractions of Leucaena leucocephala. Seed against Gastrointestinal Sheep Nematodes. Pharmaceutical Biology, 43(7): 599-604.

ATOLANI, O. and FABIYI, O. A. 2020. Plant Parasitic Nematodes Management Through Natural Products: Current Progress and Challenges. In: ANSARI, R. A., RIZVI, R. and MAHMOOD, I. (Eds.). Management of Phytonematodes: Recent Advances and Future Challenges. Springer, pp. 297-315.

CABI. 2001. Crop protection compendium. Global module. $3^{\text {rd }}$ Edition. Wallingford, UK: CAB International Publishing.

CAVENESS, F. E. 1975. A simple siphon method for separating nematodes from excess water. Nematropica, 5(2): 30-32.

CHEN, C.-Y. and WANG, Y.-D. 2010. Polyprenol from the Whole Plants of Leucaena leucocephala. Journal of Environmental Protection, 1(1): 70-72.

DARAMOLA, F. Y., AFOLAMI, S. O., IDOWU, A. A. and ODEYEMI, I. S. 2013b. Effects of Poultry Manure and Carbofuran Soil Amendments on Soil Nematode Population and yield of Pineapple. International Journal of Agricultural Science, 3(4): 294-307.

DEODHAR, U. P., PARADKAR, A. R. and PUROHIT, A. P. 1998. Preliminary evaluation of Leucaena leucocephala seed gum as a tablet binder. Drug Dev. Ind. Pharm., 24(6): 577-582.

DONCASTER, C. C. 1962. A counting dish for nematodes. Nematologica, 7(4): 334-336.

EISLER, R. 1985. Carbofuran Hazards to Fish, Wildlife, and Invertebrates: A Synoptic Review. Report 3; Biological Report 85(1.3). Contaminant Hazard Reviews. Laurel, MD: U.S. Department of the Interior, Fish and Wildlife Service.

EUROPEAN COMMISION. 2015. Commission Regulation (EU) 2015/399 of 25 th February 2015 amending Annexes II, III and V to Regulation (EC) No. 396/2005 of the European Parliament and of the Council as regards maximum residue levels for 1,4-dimethylnaphthalene, benfuracarb, carbofuran, carbosulfan, ethephon, fenamidone, fenvalerate, fenhexamid, furathiocarb, imazapyr, malathion, picoxystrobin, spirotetramat, tepraloxydim and trifloxystrobin in or on certain products Text with EEA relevance. Brussels: European Commission.

FABIYI, O. A., ATOLANI, O. and OLATUNJI, G. A. 2012. Nematicidal Activity of Alstonia boonei and Bridelia ferruginea Leaves. Albanian Journal of Agricultural Science, 11(2): 105-114.

FABIYI, O. A. 2018. Management of Meloidogyne incognita infected Tomato Plants with Agricultural Wastes. Bulletin of the Institute of Tropical Agriculture, 41: 15-20.

FABIYI, O. A., OLATUNJI, G. A., OSUNLOLA, O. S. and UMAR, K. A. 2018. Efficacy of Agricultural Wastes in the Control of Rice Cyst Nematode (Heterodera sacchari). Agriculturae conspectus scientificus, 83(4): 329-334.

FABIYI, O. A. 2019. Management of Groundnut (Arachis hypogea) Root-knot nematode (Meloidogyne incognita): Effect of Prosopis africana Pods. Indian Journal of Nematology, 49(2): 214-216.

FABIYI, O. A., SALIU, O. D., CLAUDIUS-COLE, A. O., OLANIYI, I. O., OGUNTEBI, O. V. and OLATUNJI, G. A. 2020a. Porous starch citrate biopolymer for controlled release of carbofuran in the management of root knot nematode Meloidogyne incognita. Biotechnology Reports, 25: e00428.

FABIYI O. A., OLATUNJI, G. A., ATOLANI, O. and OLAWUYI, R. O. 2020b. Preparation of bio-nematicidal nanoparticles of Eucalyptus officinalis for the control of cyst nematode (Heterodera sacchari). Journal of Animal and Plant Science, 30(5): 1172-1177.

FABIYI, O. A., ATOLANI, O. and OLATUNJI, G. A. 2020c. Toxicity effect of Eucalyptus globulus to Pratylenchus spp. of Zea mays. Sarhad Journal of Agriculture, 36(4): 1244-1253.

FABIYI, O. A. 2020. Growth and yield response of groundnut Arachis hypogaea (Linn.) under Meloidogyne incognita infection to furfural synthesised from agro-cellulosic materials. Journal of Tropical Agriculture, 58(2): 241-245.

GUDUGI, I. A. S., ODOFIN, A. J., ADEBOYE, M. K. A. and OLADIRAN, J. A. 2012. Agronomic characteristics of tomato as influenced by irrigation and mulching. Advances in Applied Science Research, 3(5): 2539-2543.

HASSAN, R. A., TAWFIK, W. A. and ABOU-SETTA, L. M. 2014. The flavonoid constituents of Leucaena leucocephala. growing in Egypt, and their biological activity. African Journal of traditional and complementary alternative medicine, 11(1): 67-72.

HUSSEY, R. S. and BAKER, K. R. 1973. A comparison of methods of collecting inocula of Meloidogyne spp. including a new technique. Plant Disease Reporter, 57(12): 1025-1028.

MACKEEN, M. M., ALI, A. M., ABDULLAH, M. A., NASIR, R. M., MAT, N. B., RAZAK, A. R. and KAWAZU, K. 1997. Antinematodal activity of some Malaysian plant extracts against the pine wood nematode. Bursaphelenchus xylophilus. Pesticide Science, 51(2): 165-170.

MAI, W. F. and LYON, H. H. 1975. Pictorial key to genera of plant parasitic nematodes. $4^{\text {th }}$ Edition. Cornerstone Publishing Associates. A division of Cornell University Press. 
MANPRAKASH. 2007. List of pesticides and maximum residue limits. The Japan Food Chemical Research Foundation. Available at: apeda. gov.in/apeda website/Announcements/ List pesticides_ Maximum Residue limits. pdf. Microsoft Word - List of pesticides and Maximum residue limits.doc [Accessed: 2021, July 15].

MIN, L., HASHI, Y., YUANYUAN, S. and JINMING, L. 2006. Determination of carbamate and organophosphorus pesticides in fruits and vegetables using liquid chromatography-mass spectrometry with dispersive solid phase extraction. Chinese Journal of Analytical Chemistry, 34(7): 941-945.

NICOSIA, S., CARR, N., GONZALES, D. A. and ORR, M. K. 1991. Off-Field Movement and Dissipation of Soil-Incorporated Carbofuran from Three Commercial Rice Fields. J. Environ Qual., 20(3): 532-539.

OAKES, A. J. 1968. Leucaena leucocephala-description, culture, utilization. Advancing Frontiers of Plant Sciences Series, Vol. 20.

OLIVEIRA, L. M. B, BEVILAQUA, C. M. L, MACEDO, I. T. F, MORAIS, S. M., MONTEIRO, M. V. B. and CAMPELLO, C. C. 2011. Effect of six tropical tanniferous plant extracts on larval exsheathment of Haemonchus conturtus. Rev Braz. Parasitol. Vet., 20(2): 155-160.

SALEM, A.-F. Z., SALEM, M. Z., GONZALEZ-RONQUILLO, M., CAMACHO, L. M. and CIPRIANO, M. 2011. Major chemical constituents of Leucaena leucocephala and Salix babylonica leaf extract. Journal of Tropical Agriculture, 49(1-2): 95-98.

STIRLING, G. R. and PATTISON, A. B. 2008. Beyond chemical dependency for managing plant parasitic nematodes. Examples from banana, pineapple and vegetable industries of tropical and subtropical Australia. Aust. Plant Pathol., 37: 254-267.

WHITEHEAD, A. G. and HEMNING, J. R. 1965. A Comparison of Some Quantitative Methods of Extracting Small Vermiform Nematodes from Soil. Ann. Appl. Biol., 55(1): 25-38.

UNITED STATE ENVIRONMENTAL PROTECTION AGENCY (US EPA). 1990. Drinking water criteria document on carbofuran. Prepared under Program No. 1524 for contract 68-C8-0033 by ICAIR, Life Systems, Inc. Cleveland, Ohio: U.S. Environmental Protection Agency.

Contact information

Oluwatoyin Adenike Fabiyi: fabiyitoyinike@hotmail.com (corresponding author) Gabriel Ademola Olatunji: m_ade49@yahoo.com 